\title{
HUBUNGAN PERAWATAN TALI PUSAT DENGAN KEJADIAN INFEKSI PADA BAYI BARU LAHIR DI RSUD Dr. PIRNGADI MEDAN 2019
}

\author{
Rani Kawati Damanik ${ }^{1}$, Linda ${ }^{2}$ \\ ${ }^{1,2}$ Program Studi Ilmu Keperawatan, Universitas Sari Mutiara Indonesia \\ e-mail: rani140387@gmail.com, lindasikessu@gmail.com
}

\begin{abstract}
Umbilical cord care is one treatment procedure that aims to treat the umbilical cord in newborns to keep it dry and prevent infection. Improper treatment of the umbilical cord in an infant will experience an infectious disease. This study uses a correlation design with a cross sectional approach is something that connects / analyzes the variables that aim to determine the relationship of umbilical cord care with the incidence of infection in newborns (BBL) in RSUD Dr. Pirngadi Hospital Medan 2018, with a sample of 35 respondents. The instruments included demographic data, 20 umbilical cord care questionnaires and observation sheets for infection. Based on the results of this study, the majority of people doing good umbilical cord care (score 14-20) as many as 30 (85.7\%) while the minority of respondents doing umbilical cord care enough (score 7-13) as many as 5 people (14.2\%). the majority did not experience an infection score of O (zero) as many as 33 people (94.3\%) and the minority experienced infection score 1-5 as many as 2 people (5.7\%). Based on Chi Square test, $p=0.017<0.05$ means that Ho is rejected and Ha is accepted. This shows a relationship between cord care and the incidence of infection in newborns (BBL). It is expected that nurses to carry out umbilical cord care measures more effectively in accordance with the SOP so as to avoid the number of infections in newborns and the next researcher makes an observation sheet in measuring cord care performed by nurses.
\end{abstract}

Keywords: Care, umbilical cord, infection, newborns (BBL)

\section{PENDAHULUAN}

Perawatan tali pusat adalah tindakan perawatan yang bertujuan merawat tali pusat pada bayi baru lahir agar tetap kering dan mencegah terjadinya infeksi. Perawatan tali pusat yang tidak benar pada bayi akan mengalami penyakit infeksi yang akan mengakibatkan kematian. Penyakit ini disebabkan karena masuknya spora kuman tetanus ke dalam tubuh melalui tali pusat, baik dari alat yang tidak steril, pemakaian obat-obatan, bubuk atau daun-daunan yang ditaburkan ke tali pusat sehingga dapat mengakibatkan infeksi (Ronald, 2012).
Penyakit infeksi merupakan salah satu penyebab utama kematian pada bayi. infeksi tali pusat telah menjadi penyebab kesakitan dan kematian secara terus menerus di berbagai negara. setiap tahunya 500.017 bayi meninggal karena tetanus neonatorum dan 460.017 meninggal akibat infeksi bakteri (Sodikin, 2013). Di Asia Tenggara diperkirakan sekitar 220.017kematian bayi disebabkan karena perawatan tali pusat yang kurang bersih dan tidak steril (Saipuddin, 2014).

Tingginya angka kesakitan dan kematian bayi baru lahir di seluruh dunia yang 
disebabkan oleh infeksi. Pada tahun 2017

World Health Organization (WHO) menemukan angka kematian bayi sebesar 560.000, sedangkan di Afrika angka kematian bayi yang disebabkan infeksi tali pusat berkisar $126.000 \quad(21 \%)$, Asia Tenggara diperkirakan ada 220.017kematian bayi yang disebabkan perawatan tali pusat yang kurang bersih (Wihono, 2017). Sehingga menurut Dore (2015) tidak merekomendasikan pembersihan tali pusat menggunakan alkohol karena memperlambat penyembuhan dan pengeringan luka.

Salah satu upaya untuk mencegah infeksi tali pusat dan tetanus neonatorum adalah perawatan tali pusat. Perawatan tali pusat adalah tindakan perawatan yang bertujuan untuk merawat tali pusat pada bayi baru lahir agar tetap kering dan mencegah terjadinya infeksi. Perawatan tali pusat sangat penting diketahui oleh ibu terutama oleh ibu melahirkan (post partum) agar ibu dapat memberikan perawatan yang maksimal pada bayi sehingga bayi dapat tumbuh dengan baik dan sehat, tidak terinfeksi melalui tali pusatnya (Yuspita, 2017).

Perawatan tali pusat sangat penting di lakukan terutama oleh ibu melahirkan karena ibu yang lebih mengetahui perkembangan bayi ssetiap harinya. Perawatan tali pusat yang baik seperti menghindari penggunaan bedak dermatol, dan penggunaan ramuan tradisional yang kurang memperhatikan kesterilannya sangat penting (Depkes RI, 2016). Kenyataan di masyarakat masih banyak ibu yang mengikuti tradisi budaya yang ada di masyarakat. Misalnya meletakkan atau membalutkan ramuan tradisonal ke tali pusat supaya tali pusat cepat lepas (puput) atau ditutupi dengan koin agar pusat tidak bodong. Padahal tindakan tersebut tidak perlu dilakukan justru dapat membahayakan. Sehingga jika diberikan ramuan, bubuk kopi, koin dapat menularkan kuman. Akibatnya terjadi infeksi atau tetanus yang sangat membahayakan karena tingkat mortalitasnya tinggi (Zacharia, 2016).

Perawatan tali pusat yang baik dan benar akan menimbulkan dampak positif yaitu tali pusat akan puput pada hari ke-5 dan hari ke7 tanpa ada komplikasi, sedangkan dampak negatif dari perawatan tali pusat yang tidak benar adalah bayi akan mengalami penyakit tetanus neonatorum. Tujuan perawatan tali pusat adalah untuk mencegah terjadinya penyakit tetanus pada bayi baru lahir yang disebabkan karena masuknya spora kuman tetanus ke dalam tubuh melalui tali pusat baik dari alat, pemakaian obat-obatan, bubuk atau daun yang di taburkan ke tali pusat sehingga dapat mengakibatkan infeksi (Depkes RI, 2015).

Merawat tali pusat berarti menjaga agar luka tersebut tetap bersih, tidak terkena kencing, kotoran bayi, atau tanah. Bila kotor, luka tali pusat di cuci dengan air bersih yang mengalir dan segera keringkan dengan/kasa bersih dan kering. Tidak boleh 
membubuhkan atau mengoleskan ramuan, abu dapur, dan sebagainya pada luka tali pusat sebab dapat menyebabkan infeksi dan tetanus yang dapat berakhir dengan kematian neonatal. Infeksi tali pusat merupakan faktor resiko untuk terjadinya tetanus neonatorum (Depkes RI, 2016).

Berdasarkan survei pendahuluan yang dilakukan pada tanggal 15 Februari 2018 di Rumah Sakit Umum Dr. Pirngadi Medan diperoleh jumlah penderita infeksi tali pusat tahun 2016 sebanyak 20 kasus, sedangkan tahun 2017 terdapat 15 kasus. Hal ini disebabkan karena belum optimalnya perawat dalam melakukan cuci tangan sebelum dan sesudah menyentuh bayi dalam melakukan perawatan tali pusat. Infeksi tali pusat juga disebabkan karena bayi yang memakai pempes yang terkena air seni dapat menyebabkan tali pusat tertekan dan kemerahan sehingga menyebabkan infeksi tali pusat. Berdasarkan latar belakang di atas, peneliti tertarik dalam melakukan penelitian yang berjudul hubungan perawatan tali pusat dengan kejadian infeksi pada bayi baru lahir.

\section{METODE}

Penelitian menggunakan metode korelasi dengan menggunakan pendekatan cross sectional. Dengan tujuan untuk mengetahui hubungan perawatan tali pusat dengan kejadian infeksi pada bayi baru lahir (BBL) di RSUD Dr. Pirngadi Medan 2018.
Populasi dalam penelitian ini adalah perawat dan bidan yang bekerja di ruangan neonati sebanyak 35 orang yaitu 12 orang perawat dan 23 bidan. Tehnik pengambilan sampel penelitian ini digunakan cara total sampling sehingga sampel sebanyak 35 orang.

Instrumen berisi ini kuesioner perawatan tali pusat sebanyak 20 soal dimana jawaban ya' diberikan nilai 1 dan tidak maka nilai nya 0 . Analisa data menggunakan uji Chi square.

\section{HASIL DAN PEMBAHASAN}

\section{Hasil Penelitian}

\section{A. Univariat}

1. Karakteristik Responden

Tabel 1.

Distribusi Frekuensi Karakteristik

Responden Berdasarkan Usia,

Pendidikan, Pengalaman Kerja dan Jenis

Tenaga Kesehatan di RSUD Dr. Pirngadi Medan Tahun $2018(n=35)$

\begin{tabular}{|c|c|c|c|}
\hline No. & $\begin{array}{c}\text { Karakteristik } \\
\text { Responden }\end{array}$ & $f$ & $(\%)$ \\
\hline \multirow[t]{6}{*}{1.} & Usia & & \\
\hline & $20-35$ tahun & 14 & 40.0 \\
\hline & $36-45$ tahun & 18 & 51.4 \\
\hline & $46-55$ tahun & 3 & 8.6 \\
\hline & $>56$ tahun & 0 & 0 \\
\hline & Total & 35 & 100 \\
\hline \multirow[t]{5}{*}{2.} & Pendidikan & & \\
\hline & D3 & 29 & 82.9 \\
\hline & S1 & 6 & 17.1 \\
\hline & $\mathrm{S} 2$ & 0 & 0 \\
\hline & Total & 35 & 100 \\
\hline \multirow[t]{6}{*}{3.} & Pengalaman Kerja & & \\
\hline & $1-5$ tahun & 8 & 22.9 \\
\hline & 6-10 tahun & 7 & 20.0 \\
\hline & $11-15$ tahun & 15 & 42.9 \\
\hline & $>16$ tahun & 5 & 14.2 \\
\hline & Total & 35 & 100 \\
\hline \multirow[t]{4}{*}{4.} & Jenis Tenaga & & \\
\hline & Kesehatan & 23 & 65.7 \\
\hline & 1. Bidan & 12 & 34.3 \\
\hline & $\begin{array}{l}\text { 2. Perawat } \\
\text { Total }\end{array}$ & 35 & 100 \\
\hline
\end{tabular}


Berdasarkan hasil penelitian, tabel di atas menunjukkan bahwa mayoritas responden berada pada usia 36-45 tahun sebanyak 18 orang (51.4\%) dan minoritas responden berada pada usia 46-55 tahun sebanyak 3 orang $(8.6 \%)$. Selanjutnya mayoritas pendidikan D3 sebanyak 29 $(82.9 \%)$ dan minoritas berpendidikan $\mathrm{S} 1$ sebanyak 6 orang (17.1\%). Mayoritas pengalaman kerja11-15 tahun sebanyak 15 orang $(42.9 \%)$ dan minoritas pengalaman kerja >16 tahun sebanyak 5 orang (14.2\%). Berdasarkan jenis tenaga kesehatan maka mayoritas bidan sebanyak 23 orang (65.7\%) dan minoritas perawat sebanyak 12 orang $(34.3 \%)$.

\section{Perawatan Tali Pusat}

\section{Tabel 2.}

Distribusi frekuensi Perawatan Tali Pusat di RSUD Dr. Pirngadi Medan Tahun 2018 $(\mathbf{n = 3 5})$

\begin{tabular}{rlrr}
\hline No. & $\begin{array}{c}\text { Perawatan Tali } \\
\text { Pusat }\end{array}$ & \multicolumn{1}{c}{$\boldsymbol{f}$} & $(\boldsymbol{\%})$ \\
\hline 1. & Baik (skor 14-20) & 30 & 85.7 \\
2. & Cukup (skor 7-13) & 5 & 14.3 \\
3. & Kurang (skor 0-6) & 0 & 0 \\
\hline & Total & 35 & 100
\end{tabular}

Berdasarkan hasil penelitian, tabel di atas menunjukkan bahwa mayoritas responden melakukan perawatan tali pusat Baik (skor 14-20) sebanyak 30 (85.7\%) sedangkan minoritas responden melakukan perawatan tali pusat cukup (skor 7-13) sebanyak 5 orang (14.3\%).

\section{Kejadian Infeksi tali pusat}

Tabel 3.

Distribusi Frekuensi Kejadian Infeksi Tali Pusat di RSUD Dr. Pirngadi Medan Tahun $2018(n=35)$

\begin{tabular}{clcc}
\hline No. & \multicolumn{1}{c}{ Kejadian infeksi } & $\boldsymbol{f}$ & $\mathbf{( \% )}$ \\
\hline 1. & $\begin{array}{l}\text { Terjadi Infeksi } \\
\text { (terdapat salah satu } \\
\text { tanda infeksi) skor 1-5 }\end{array}$ & 2 & 5.7 \\
\hline 2. & $\begin{array}{l}\text { Tidak Terjadi Infeksi } \\
\text { (tidak terdapat tanda } \\
\text { infeksi) skor 0 (nol) }\end{array}$ & 33 & 94.3 \\
\hline & Total & 35 & 100 \\
\hline
\end{tabular}

Berdasarkan hasil penelitian, tabel di atas menunjukkan bahwa mayoritas responden tidak mengalami terjadinya infeksi skor 0 (nol) sebanyak 33 orang (94.3\%) dan minoritas responden mengalami terjadinya infeksi skor 1-5 sebanyak 2 orang $(5.7 \%)$.

\section{B. Bivariat}

Tabel 4.

Distribusi Frekuensi Hubungan Perawatan Tali Pusat dengan kejadian infeksi di RSUD Dr. Pirngadi Medan Tahun 2018 (n=35)

\begin{tabular}{lcccccccc}
\hline \multirow{2}{*}{$\begin{array}{l}\text { Perawatan } \\
\text { Tali Pusat }\end{array}$} & \multicolumn{4}{c}{ Kejadian Infeksi } & & \multicolumn{1}{c}{} \\
\cline { 2 - 5 } & $\begin{array}{c}\text { Terjadi } \\
\text { Infeksi }\end{array}$ & $\begin{array}{c}\text { Tdk } \\
\text { Terjadi } \\
\text { Infeksi }\end{array}$ & Total & $\begin{array}{c}\boldsymbol{p} \\
\text { value }\end{array}$ \\
\cline { 2 - 7 } & $\boldsymbol{f}$ & $\mathbf{\%}$ & $\boldsymbol{f}$ & $\mathbf{\%}$ & $\boldsymbol{f}$ & $\mathbf{\%}$ & \\
\hline Baik & 0 & 0 & 30 & 85.7 & 30 & 85.7 & 0.017 \\
Cukup & 2 & 5.7 & 3 & 8.6 & 5 & 14.3 & \\
\hline Total & 2 & 5.7 & 33 & 94.3 & 35 & 100 & \\
\hline
\end{tabular}

Berdasarkan hasil penelitian, tabel 4 menunjukkan bahwa mayoritas responden tidak mengalami terjadinya infeksi dengan melakukan perawatan tali pusat baik (skor 14-20) yaitu sebanyak 30 orang (85.7\%), dan responden tidak mengalami terjadinya infeksi dengan melakukan perawatan tali 
pusat cukup (skor 7-13) sebanyak 3 (8.6\%), sedangkan minoritas responden mengalami terjadinya infeksi dengan melakukan perawatan tali pusat cukup (skor 7-13) sebanyak $2(5.7 \%)$. Berdasarkan uji Chi Square didapatkan $\mathrm{p}=0.017<0.05$ berarti Ho ditolak dan $\mathrm{Ha}$ diterima. Ini menunjukkan bahwa ada Hubungan Perawatan Tali Pusat dengan Kejadian Infeksi Pada Bayi Baru Lahir di RSUD Dr. Pirngadi Medan Tahun 2018.

\section{Pembahasan}

\section{A. Perawatan Tali Pusat}

Melakukan perawatan tali pusat sangat penting dilakukan untuk mencegah infeksi. Tujuan perawatan tali pusat untuk mencegah terjadinya penyakit tetanus pada bayi baru lahir, agar tali pusat tetap bersih, kumankuman tidak masuk sehingga tidak terjadi infeksi pada tali pusat bayi. Penyakit tetanus ini disebabkan oleh clostridium tetani yaitu kuman yang mengeluarkan toksin (racun), yang masuk melalui luka tali pusat, karena perawatan atau tindakan yang kurang bersih (Saifuddin, 2014).

Hasil penelitian yang dilakukan oleh peneliti bahwa mayoritas responden melakukan perawatan tali pusat baik (skor 14-20) sebanyak 30 (85.7\%), dengan mayoritas responden berada pada usia 36-45 tahun sebanyak 18 orang (51.4\%), dan berpendidikan S1 sebanyak 6 orang (17.1\%) dengan mayoritas pengalaman kerja 11-15 tahun sebanyak 15 orang (42.9 \%), berdasarkan jenis tenaga kesehatan maka mayoritas bidan sebanyak 23 orang (65.7\%). Perawat dan bidan merupakan sebagai tenaga professional yang juga bertanggung jawab dalam memberikan pelayanan keperawatan. Kewenangan yang dimiliki secara mandiri maupun bekerjasama dengan anggota kesehatan lainnya (Depkes RI, 2016).

Hal ini sesuai dengan hasil penelitian Adji (2014) yang menyatakan bahwa umur seseorang sangat mempengaruhi prosesproses perkembangan mentalnya dengan baik, sehingga dengan bertambahnya umur seseorang dapat berpengaruh pada pertambahan pengetahuannya. Sedangkan tingkat pendidikan turut pula menentukan mudah tidaknya seseorang menyerap dan memahami pengetahuan yang mereka peroleh, pada umumnya semakin tinggi pendidikan seseorang maka semakin baik pula pengetahuanya. Kemudian pengalaman merupakan guru yang terbaik. Sehingga dengan semakin seseorang memiliki pengalaman maka kemampuan dalam memecahkan permasalahan yang dihadapi semakin baik, dengan kata lain seseorang tersebut semakin cekatan (Notoatmodjo, 2003).

Hal ini didukung oleh penelitian yang dilakukan oleh Yuliana, Mahpolah dan Rosyana tahun 2017 yang berjudul metode perawatan tali pusat pada bayi di ruang bayi RSUD. Ulin Banjarmasin diperoleh kesimpulan bahwa dengan melakukan 
perawatan tali pusat secara benar dapat mencegah terjadinya infeksi pada tali pusat bayi baru lahir. Perawatan tali pusat seseuai prosedural di Rumah Sakit Ulin Banjarmasin telah dilakukan sejak \pm 10 tahun terakhir dan tidak pernah dilaporkan adanya kejadian infeksi tali pusat pada bayi.

Sedangkan hasil penelitian minoritas yang diperoleh oleh peneliti bahwa, responden melakukan perawatan tali pusat cukup (skor 7-13) sebanyak 5 orang (14.3\%), mayoritas pendidikan D3 sebanyak 29 (82.9\%). Minoritas pengalaman kerja $>16$ tahun sebanyak 5 orang (14.3\%). Minoritas responden berada pada usia 46-55 tahun sebanyak 3 orang (8.6\%), minoritas perawat sebanyak 12 orang (34.3\%).

Sesuai dengan Notoatmodjo (2003) bahwa pengetahuan atau kognitif merupakan domain yang sangat penting akan terbentuknya tindakan seseorang. Pengetahuan yang baik akan menjadi dasar untuk terbentuknya keterampilan yang baik pula. Kemampuan untuk menyerap pengetahuan atau ilmu akan berdampak pada kehidupan seseorang. Pengetahuan atau kognitif merupakan domain yang sangat penting untuk terbentuknya tindakan atau keterampilan seseorang.

Berdasarkan analisis dari tinjauan teori dengan hasil penelitian yang diperoleh maka faktor usia, tingkat pendidikan dan pengalaman kerja mempengaruhi seseorang dalam melakukan tindakan. Sehinggga semakin tinggi tingkat pendidikan dan semakin lamanya pengalaman kerja seseorang maka akan semakin profesional seseorang dalam melakukan tindakan. Akan tetapi hal ini tidak sesuai dengan usia seseorang, dimana semakin lanjut usia seseorang maka akan mempengaruhi dalam melakukan tindakan yang optimal.

\section{B. Kejadian Infeksi}

Kejadian infeksi tali pusat pada dasarnya dapat dicegah dengan melakukan perawatan tali pusat yang baik dan benar, yaitu dengan prinsip perawatan kering dan bersih. Banyak pendapat tentang cara terbaik untuk merawat tali pusat. Upaya untuk mencegah infeksi tali pusat sesungguhnya merupakan tindakan sederhana yang penting adalah tali pusat dan daerah sekitarnya selalu bersih dan kering (Depkes Sumut, 2016).

Hasil penelitian yang diperoleh oleh peneliti bahwa mayoritas responden tidak mengalami terjadinya infeksi skor 1-5 sebanyak 33 orang $(94.3 \%)$. Hal ini sesuai dengan teori yang ada bahwa, infeksi tali pusat pada dasarnya dapat dicegah dengan melakukan perawatan tali pusat yang baik dan benar, yaitu dengan prinsip perawatan kering dan bersih. Sehingga dengan melakukan perawatan tali pusat dengan prosedur dapat mencegah dan mengidentifikasi pendarahan atau infeksi secara dini (Jitowijoyo, 2010).

Perawatan tali pusat harus dilakukan dengan benar, sesuai dengan prosedur dan 
harus memperhatikan kebersihan. Dampak positif dari perawatan tali pusat dengan prinsip kering dan bersih adalah bayi akan sehat dengan kondisi tali pusat bersih dan tidak terjadi infeksi serta tali pusat pupus lebih cepat, yaitu antara hari ke 7-10 tanpa ada komplikasi. Hasil perawatan tali pusat pada bayi adalah dalam keadaan sehat dan tidak ditemukan tanda infeksi (Lestari, 2013).

Berdasarkan hasil penelitian yang dilakukan oleh peneliti diperoleh bahwa minoritas responden mengalami terjadinya infeksi skor 1-5 sebanyak 2 orang (5.7\%). Menurut Mieke (2016) bahwa kejadian infeksi tali pusat pada bayi lebih sering terjadi karena masih banyak yang belum sadar pentingnya kebersihan. Kurang mendapat informasi seputar merawat tali pusat pada bayi juga sangat mempengaruhi terjadinya infeksi tali pusat.

Berdasarkan hasil penelitian yang dilakukan oleh peneliti diperoleh dari jawaban kuesioner responden bahwa terdapat sebanyak 11 orang (31\%) tidak melakukan cuci tangan sebelum melakukan perawatan tali pusat. Masih ada responden tidak melakukan pembersihan dari arah ujung ke pangkal, bila tali pusat masih basah Sebanyak 6 orang (17.1\%). Hal ini sesuai dengan teori bahwa merawat tali pusar memang harus dilakukan secara maksimal sampai tali pusar mengering dan lepas atau biasa disebut puput pusar (sekitar 7-10 hari). Caranya dengan menggunakan kapas lalu bersihkan tali pusar dan keringkan dengan menggunakan kapas kering (Saipuddin, 2014).

World Health Organization (WHO) telah merekomendasikan praktik perawatan tali pusat bersih meliputi mencuci tangan dengan air bersih dan sabun baik sebelum dan sesudah perawatan dilakukan, serta menjaga tali pusat agar tetap kering dengan paparan udara. Praktik lain yang juga dapat mengurangi risiko infeksi tali pusat adalah penerapan rooming-in selama 24 jam untuk ibu dan bayi. Peningkatan frekuensi kontak skin-to-skin akan meningkatkan kolonisasi bakteri non patogen dari flora kulit ibu ke bayi yang dipercaya dapat mengurangi risiko bayi terkena infeksi tali pusat (WHO, 2015).

Hasil penelitian menurut Yuspita. (2017), bahwa dampak negatif perawatan tali pusat apabila tali pusat tidak dirawat dengan baik, kuman akan bisa masuk sehingga terjadi infeksi yang mengakibatkan penyakit tetanus neonatorum. Tanda infeksi pada tali pusat bayi baru lahir ditandai dengan tali pusat bayi bernanah, berbau, berwarna merah, panas, bengkak dan terdapat area lembut di sekitar dasar tali pusat seukuran uang logam seratus rupiah.

Berdasarkan analisis dari tinjauan teori dengan hasil penelitian yang diperoleh maka terjadinya infeksi tali pusat disebabkan karena dalam melakukan tindakan harus dilakukan dengan benar, sesuai dengan prosedur. Menghindari infeksi tali pusat 
harus memperhatikan kebersihan yang dapat dilakukan dengan cuci tangan sebelum melakukan perawatan tali pusat. Sehingga dengan cuci tangan dapat menurunkan efek kontak skin-to-skin pada bayi untuk menghindari infeksi tali pusat.

\section{Hubungan Perawatan Tali Pusat dengan Kejadian Infeksi}

Hasil penelitian yang dilakukan oleh peneliti, maka diperoleh bahwa mayoritas responden tidak mengalami terjadinya infeksi dengan melakukan perawatan tali pusat baik (skor 14-20 ) yaitu sebanyak 30 orang (85.7\%), dan responden tidak mengalami terjadinya infeksi dengan melakukan perawatan tali pusat cukup (skor 7-13) sebanyak 3 (8.8\%), sedangkan minoritas responden mengalami terjadinya infeksi dengan melakukan perawatan tali pusat cukup (skor 7-13) sebanyak 2 (5.7\%). Berdasarkan uji Chi Square didapatkan $\mathrm{p}=$ $0.017<0.05$ berarti Ho ditolak dan $\mathrm{Ha}$ diterima. Ini menunjukkan bahwa ada Hubungan Perawatan Tali Pusat dengan Kejadian Infeksi Pada Bayi Baru Lahir di RSUD Dr.Pirngadi Medan Tahun 2018.

Berdasarkan teori bahwa tali pusat merupakan jalan masuk utama infeksi sistemik pada bayi baru lahir. Risiko infeksi tali pusat mudah dihindari dengan perawatan tali pusat yang baik. Dampak dari perawatan tali pusat yang tidak benar adalah bayi akan mengalami tetanus neonatorum mengakibatkan kematian.
Sehingga melaksanakan perawatan tali pusat diharapkan perawat mempunyai kemampuan memberikan pelayanan yang berkualitas (Wibowo, 2013).

Hal ini sejalan dengan penelitian yang dilakukan oleh Rejeki, Machmudah dan Juwarningsih yang berjudul praktik perawatan tali pusat dengan kejadian infeksi tali pusat bayi baru lahir di Semarang tahun 2017 menunjukkan bahwa ada hubungan yang signifikan antara pengetahuan tentang perawatan tali pusat dengan kejadian infeksi tali pusat bayi baru lahir dengan nilai $p$ value $0,003(\alpha<0,05)$. Hal ini berarti semakin baik pengetahuan tentang perawatan tali pusat maka semakin tidak terinfeksi tali pusat bayi baru lahir, meskipun pengetahuan perawatan tali pusat baik tidak selalu bayi tidak terinfeksi tali pusat dan infeksi tali pusat yang terjadi juga tidak selalu terjadi karena pengetahuan kurang tentang perawatan tali pusat.

Berdasarkan tinjauan teori dinyatakan bahwa perawatan tali pusat merupakan salah satu tindakan keperawatan yang bertujuan merawat tali pusat pada bayi baru lahir agar tetap kering dan mencegah terjadinya infeksi. Perlunya upaya menggunakan dan meningkatkan metode dalam pelayanan kesehatan dan peningkatan pengetahuan agar dalam melakukan perawatan tali pusat pada bayi dengan baik dan benar sehingga dapat menurunkan atau mencegah resiko terjadinya infeksi pada tali pusat (Muctar, 2013). 
Hasil penelitian didukung oleh penelitian yang dilakukan oleh Munjiati (2013) bahwa perawatan tali pusat sebagian besar responden tidak melakukan dengan benar dan bayi sebagian besar tidak terinfeksi tali pusat. Hasil penelitian ini sejalan dengan penelitian yang dilakukan oleh Setyaningrum (2012) tentang faktor yang mempengaruhi kejadian infeksi tali pusat, didapatkan hasil bahwa ada hubungan yang signifikan antara pengetahuan petugas kesehatan tentang perawatan tali pusat dengan kejadian infeksi tali pusat nilai $p$ value 0,012 .

Berdasarkan analisis dari tinjauan teori dengan hasil penelitian yang dipeoleh maka ada hubungan yang signifikan antara perawatan tali pusat dengan kejadian infeksi. Hal ini sesuai antara teori yang ada dengan hasil penelitian yang dilakukan dan peneliti yang terdahulu. Dengan dilakukannya tehnik perawatan tali pusat yang sesuai standar dapat mencegah kejadian infeksi pada bayi.

\section{KESIMPULAN DAN SARAN}

\section{Kesimpulan}

Berdasarkan hasil analisis data dan pembahasan hasil penelitian mengenai kepuasan kepuasan perawat pada perawatan tali pusat dengan kejadian infeksi pada bayi baru lahir dengan nilai signifikan $(p=0.17)$, sehingga $(p<0.05)$, maka Ha diterima dan Ho ditolak, maka dapat disimpulkan bahwa ada hubungan perawatan tali pusat dengan kejadian infeksi pada bayi baru lahir.

\section{Saran}

Bagi perawat yang bekerja di ruang neonati agar dalam melaksanakan tindakan perawatan tali pusat lebih efektif sesuai dengan SOP sehingga dapat menghindari angka terjadinya infeksi pada bayi baru lahir.

Bagi rumah sakit dalam menentukan kebijakan untuk memberikan pelatihan tentang perawatan tali pusat, sehingga perawat akan lebih terampil, cekatan dan dalam berkomunikasi lebih baik lagi dalam memberikan pelayanan pada pasien.

Bagi penelitian selanjutnya disarankan agar membuat lembar observasi dalam mengukur perawatan tali pusat yang dilakukan oleh perawat sehingga hasil penelitian lebih optimal dan menghindarkan bias dari jawaban responden.

\section{DAFTAR PUSTAKA}

Adji. (2014). Buku Saku Manajemen Masalah Bayi Baru Lahir Panduan Untuk Dokter, Perawat dan Bidan. Jakarta: EGC.

Cunningham et all. (2015). Obstetri williams. Yogyakarta: Mitra Pustaka.

Danandjaja, (2013). Biologi reproduksi kehamilan dan persalinan. Edisi 1. Yogyakarta: Graha Ilmu.

Depkes RI. (2015). Asuhan persalinan normal. Jakarta: Depkes RI.

Depkes Sumut. (2016). Data infeksi tali pusat pada bayi. Medan : Depkes Sumut.

Hidayat, A.A.A. (2009). Ilmu Kesehatan Anak untuk Pendidikan Kebidanan. Jilid I. Jakarta: Salemba Medika.

Jitowijoyo, S., Kristiyanasari, W. (2010). Asuhan Keperawatan Neonatus dan Anak. Cetakan I. Yogyakarta: Muha Medika. 
JNPK-KR, (2012): Buku acuan pelatihan klinik Asuhan persalinan normal. Jakarta: Salemba Medica.

Kementerian Kesehatan RI. 2014. Buku Kesehatan Ibu dan Anak. Jakarta: Kemenkes dan JICA.

Lestari, (2013) . Panduan belajar: keperawatan ibu-bayi baru lahir ed.3. Jakarta : EGC.

Lissauer. (2013). Perawatan tali pusat kering pada bayi. http:Kesehatan RI/2013/12/ infeksi-tali-pusat.html. diakses tanggal 20 November 2015.

Meiliya, E., Pamilih, E.K. (2008). Buku Saku Manajemen Masalah Bayi Baru Lahir Panduan Untuk Dokter, Perawat dan Bidan. Jakarta: EGC

Mieke, (2016). Manajemen kebidanan pada infeksi tali pusat. Diakses dari http:ulfahsita.co.id/2013/12/manajemenkebidanan-pada-infeksi-tali-pusat.html. diakses tanggal 18 November 2015.

Monchtar. (2015). Sinopsis obstetri, Jakarta: EGC.

Muslihatun. (2012). Asuhan Neonatus Bayi dan Balita.Yogyakarta : Fitramaya.

Notoatmodjo, S. (2010). Metodologi Penelitian Kesehatan. Edisi Revisi Cetakan I. Jakarta: PT. Rineka Cipta.

Paisal. (2013). Mencegah infeksi tali pusat. http: pencegahan-infeksi-tali-pusat.html.

Ronald. (2012). Pedoman perawatan balita. Bandung : Nuansa Aulia.

Rosalin,dkk. (2015). Terjadinya infeksi tali pusat pada bayi. Vol. 1, No. 1 : 23-30.

Rustam. M. (2015). Sinopsis obstetri. Jakarta: EGC.

Saipuddin. (2014). Pelayanan kesehatan ibu dan bayi. Jakarta :EGC.

Sarwono. P, (2014). Ilmu kebidanan. Jakarta: PT. Bina Pustaka.

SDKI (2017). Survei dinas kesehatan Indonesia. Jakarta : Survei Dinas Indonesia.

Sodikin. (2015). Buku saku perawatan tali pusat. Jakarta : EGC.

Simkin et all (2016). Panduan lengkap kehamilan dan melahirkan bayi. Jakarta : Arcan.

Sinsin. L. (2014). Tingkat Kejadian Infeksi. Bandung : Nuansa Aulia.
Wibowo, N, \& Saipuddin (2013). Plasenta tali pusat, selaput janin dan cairan amnion. Jakarta : FKUI.

Wihono P. A (2017). Gambaran cara perawatan tali pusat dan lama waktu pelepasan tali pusat diwilayah kerja puskesmas kecamatan bakti sukoharjo. Skripsi : Universitas Muhammadiyah Surakarta.

WHO, (2017). Care of the umbilical cord. A review of the evidence. Terdapat pada: www.who.int/csr/disease/swineflu/en/ind e x.html.

Yuspita (2017). Sepsis pada neonatus (sepsis neonatal). Sari Pediatri, Vol. 2, No. 2 : 96-102.

Zacharia. (2016). Tata cara pemotongan tali pusat. Yogyakarta: Nuha Medika.

Wardhani et all, (2015), Perawatan bayi baru lahir. http//www. tabloidnakita.com, diperoleh tanggal 10 Januari, 2015).

Winkjosastro, H. (2007). Ilmu Kebidanan. Cetakan 5. Jakarta: Yayasan Bina Pustaka Sarwono Prawirohardjo. 